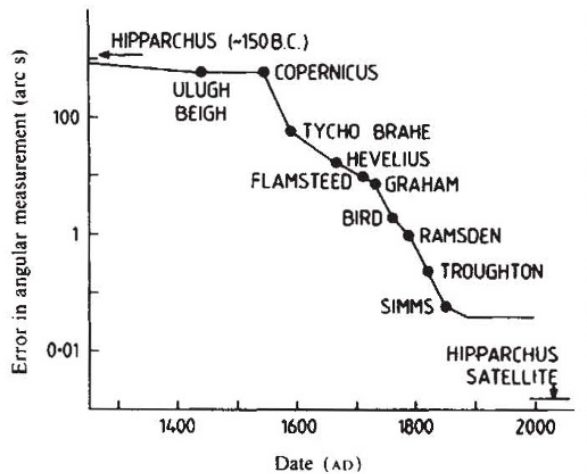

The observational error in the astronomical measurement of stellar and planetary positions plotted logarithmically against the year. The data have come from H. Mineur (see H.T. Pledge, Science since 1500, HMSO; 1939), A. Chapman (J. hist. Astr. 14, 133; 1983) and European Space Agency DP/PS(78)13.

also limited by the 1-arc-min resolution power of the human eye. The adoption of the telescopic sight and the micrometer overcame this barrier and the angular error fell to 15 arc s by 1700 and 8 arc s by 1725 . This made it possible to detect stellar aberration (small positional wanderings due to the vectorial addition of the velocity of light to the Earth's orbital velocity) and nutation (an 18.6-year wobble in the Earth's spin axis produced by the gravitational influence of the Moon and planets).

The third breakthrough came in the late eighteenth century. Instrument-makers Jesse Ramsden and Edward Troughton replaced the quadrant with the full circle. Circles could be rotated thus enabling the graduations to be cross-checked with micrometer microscopes. By 1800 the error had been reduced to 0.5 arc s. 1850 saw the installation of G.B. Airy's transit circle at Greenwich. Troughton and Simms were responsible for the optics and instrumentation. Six cross-checking micrometermicroscopes placed at $60^{\circ}$ intervals around the circle gave a final accuracy of 0.06 arc $s$.

Unfortunately the accuracy of astronomical measurements of stellar position has only improved very slightly since then. The accuracy of the main applications of astrometry - the motions of the Moon and planets, the kinematics and dynamics of the galaxy, stellar mass determination and the rotation of the Earth and polar wandering - have also remained almost stationary. The next leap forwards will come from the ESA Hipparchus satellite. This is designed to measure stellar position to an accuracy of \pm 0.0015 arcs and stellar parallax to \pm 0.002 arcs.

David $W$. Hughes is in the Department of Physics, University of Sheffield, Sheffield S3 $7 R H$.

\title{
Archaeology
}

\section{Setting Stonehenge straight}

\section{from Christopher Chippindale}

FOR years the dismal state of Stonehenge, Europe's premier prehistoric monument, has been a disgrace - and an embarrassment to British archaeology. Always the most famous English ancient monument, it has become even more popular since archaeo-astronomers tried to identify it as a neolithic observatory. Yet many of its visitors, up to 800,000 annually, and two-thirds of them from abroad, find the place a sad let-down hemmed in by busy main roads, approached through a nasty grey concrete tunnel, and each June the unwilling focus of an immense drug and rock music festival.

Partly it is a simple question of numbers. Stonehenge is rather a small monument the central ruin with its three standing trilithons is only thirty-five paces across and the grass there cannot survive the tramp of a million feet. Since 1978 the Department of the Environment (DoE), the government agency responsible, has closed the centre. Instead visitors are shepherded along a tarmac path, camouflaged a chemical shade of green, well away from the stones. In consequence it is impossible properly to see those features, the mortiseand-tenon joints of the lintels, the bluestone settings, the solar alignment of the axis, that make Stonehenge extraordinary and unique. And since aids for visitors are minimal, it is hard to know just what you should be looking out for.

The romantic ideal is to see Stonehenge alone, preferably by moonlight and with a storm brewing (it is still strongly recommended but is now very hard to manage). Over 200 years ago, William Stukeley, the first great student of Stonehenge, grumbled about its 'infinite number of daily visitants'. It was a famous shambles at Victorian bank holidays, with 'vanloads of uproarious humanity, dressed in all the colours of the rainbow, and in many others of aniline origin', and the dominant sound not lark-song but the crash of souvenirhunters' hammers on the stones'.

So great was the threat, during the 1920 s, of a suburban sprawl of shapeless development - bungalows, cafés, an intensive pig-farm - crowding in on Stonehenge, that a public appeal bought 700 hectares of surrounding land and gave it to the National Trust, which would preserve Stonehenge for ever in a sweep of empty chalk downland. There were schemes to suppress the main A344 road which ran a couple of metres from the Heel Stone, so that the "circle itself seems almost submerged by the congestion, vulgarity, speed, and noise". But the road stayed open and soon spawned a car-park hard by the stones. (Calls for lavatories were at first resisted: "after all, the whole Plain is available for the convenience of the public".) Over the years, more facilities have grown on that site - extra space for cars several times, lavatories (both underground and up in the air), a café, souvenir shop, and bunker for the DoE's guardians - as well as a tunnel access-way to save the dangerous crossing of the road ${ }^{2}$.

After four decades of such piecemeal growth, Stonehenge presents a classic case of how a cultural resource should not be managed. The main road across its edge is still open. The facilities are too close and too obtrusive, but because the site is cramped they are also inadequate. Management is bureaucratic and remotely directed from London, while the DoE shows no sign of imagination or initiative, or even of noticing the enormous advances being made elsewhere in managing and displaying historic monuments. It has suppressed the report of an independent working party ${ }^{3}$ which recommended new facilities at a sensible distance and on a sensible scale. Instead it wants to enlarge on the present site, which is on the land bought by public subscription expressly to prevent tasteless development. The National Trust, recently bruised by a very public row over letting the air force develop a military bunker on another of its holdings, is, with every reason, declining to cooperate. And since the National Trust is the actual landowner, it has an effective veto.

In April 1984, the DoE will lose control over Stonehenge, which will pass to a new, autonomous Historic Buildings and Monuments Commission. Certainly, the new commission will know what a disaster it inherits - one of its commissioners calls Stonehenge today a 'squalid scandal' and there is every hope it will abandon the fossil attitudes of the old regime.

The downs around Stonehenge contain, within a few square kilometres, an astonishing concentration of prehistoric sites ${ }^{4}$, currently the subject of remarkable fieldwork by Julian Richards of the Trust for Wessex Archaeology. That ancient landscape, with its barrows, henges, cursuses and boundary earthworks, is the environment into which its builders put Stonehenge. A new policy for Stonehenge gives the chance of an imaginative scheme to show the place in that context - to set it once again, as William Stukely explained in 1740, "in clean and distinct areas, distant from profane buildings and traffic" 5 .

Christopher Chippindale is at the Department of Archaeology, University of Cambridge $C B 23 D Z$.

\footnotetext{
C. Chippindale, Stonehenge Complete (London 1983). C. Chippindale, Antiquity 57, 172 (1983).

Stonehenge Working Party Report 10 the Department of the Environment (1979. unpublished).

RCHM(E). The Environs of Sionehenge (Edinburgh 1979). W. Siukeley, Stonehenge (l.ondon, 1740).
} 